\section{(6) OPEN ACCESS}

\title{
A randomised, double-blind, parallel-group study to demonstrate equivalence in efficacy and safety of CT-P13 compared with innovator infliximab when coadministered with methotrexate in patients with active rheumatoid arthritis: the PLANETRA study
}

\author{
Dae Hyun Yoo, ${ }^{1}$ Pawel Hrycaj, ${ }^{2}$ Pedro Miranda, ${ }^{3}$ Edgar Ramiterre, ${ }^{4}$ \\ Mariusz Piotrowski, ${ }^{5}$ Sergii Shevchuk, ${ }^{6}$ Volodymyr Kovalenko, ${ }^{7}$ Nenad Prodanovic, ${ }^{8}$ \\ Mauricio Abello-Banfi, ${ }^{9}$ Sergio Gutierrez-Ureña, ${ }^{10}$ Luis Morales-Olazabal, ${ }^{11}$ \\ Michael Tee, ${ }^{12}$ Renato Jimenez, ${ }^{13}$ Omid Zamani, ${ }^{14}$ Sang Joon Lee, ${ }^{15}$ HoUng Kim, ${ }^{16}$ \\ Won Park, ${ }^{17}$ Ulf Müller-Ladner ${ }^{18}$
}

\begin{abstract}
Handling editor Tore K Kvien
- Additional material is published online only. To view please visit the journal online (http://dx.doi.org/10.1136/ annrheumdis-2012-203090)

For numbered affiliations see end of article.
\end{abstract}

\section{Correspondence to} Professor Dae Hyun Yoo, Division of Rheumatology, Hanyang University Hospital for Rheumatic Diseases, 220 Wangsimni-Ro, Seongdong-Gu, Seoul 133-792, Republic of Korea; dhyoo@hanyang.ac.kr; Professor Ulf Müller-Ladner, Department of Rheumatology and Clinical Immunology, Justus Liebig University Giessen, Kerckhoff-Klinik GmbH, Benekestrasse 2-8, 61231 Bad Nauheim,

Germany;

u.mueller-ladner@kerckhoffklinik.de

Accepted 19 April 2013 Published Online First 17 May 2013

\section{Linked}

- http://dx.doi.org/10.1136/ annrheumdis-2012-203091

- http://dx.doi.org/10.1136/ annrheumdis-2012-203198

To cite: $Y o o D H$, Hrycaj $P$, Miranda P, et al. Ann Rheum Dis 2013:72: 1613-1620.

\section{ABSTRACT}

Objectives To compare the efficacy and safety of innovator infliximab (INX) and CT-P13, an INX biosimilar, in active rheumatoid arthritis patients with inadequate response to methotrexate (MTX) treatment. Methods Phase III randomised, double-blind, multicentre, multinational, parallel-group study. Patients with active disease despite MTX (12.5-25 mg/week) were randomised

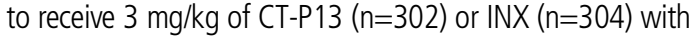
MTX and folic acid. The primary endpoint was the American College of Rheumatology 20\% (ACR20) response at week 30. Therapeutic equivalence of clinical response according to ACR20 criteria was concluded if the $95 \% \mathrm{Cl}$ for the treatment difference was within $\pm 15 \%$. Secondary endpoints included ACR response criteria, European League Against Rheumatism (EULAR) response criteria, change in Disease Activity Score 28 (DAS28), Medical Outcomes Study Short-Form Health Survey (SF-36), Simplified Disease Activity Index, Clinical Disease Activity Index, as well as pharmacokinetic (PK) and pharmacodynamic (PD) parameters, safety and immunogenicity.

Results At week 30, ACR20 responses were $60.9 \%$ for CT-P13 and $58.6 \%$ for INX $(95 \% \mathrm{Cl}-6 \%$ to $10 \%)$ in the intention-to-treat population. The proportions in CT-P13 and INX groups achieving good or moderate EULAR responses (C reactive protein (CRP)) at week 30 were $85.8 \%$ and $87.1 \%$, respectively. Low disease activity or remission according to DAS28-CRP, ACR-EULAR remission rates, $A C R 50 / A C R 70$ responses and all other $P K$ and $P D$ endpoints were highly similar at week 30 . Incidence of drug-related adverse events (35.2\% vs $35.9 \%$ ) and detection of antidrug antibodies ( $48.4 \%$ vs $48.2 \%$ ) were highly similar for CT-P13 and INX, respectively.

Conclusions CT-P13 demonstrated equivalent efficacy to INX at week 30, with a comparable PK profile and immunogenicity. CT-P13 was well tolerated, with a safety profile comparable with that of INX.

ClinicalTrials.gov Identifier NCT01217086

\section{INTRODUCTION}

Innovator infliximab (INX), a chimeric monoclonal antibody to tumour necrosis factor- $\alpha$ (TNF $\alpha)$, with demonstrated beneficial effects in rheumatoid arthritis (RA) patients, was approved in 1999. The approval of INX was based on data from the ATTRACT study. ${ }^{1}$

The availability of targeted biological therapies has revolutionised the treatment of RA. However, the significant cost of these medications creates a major barrier that limits universal access to these effective therapeutic agents. This has led to interest in developing biosimilar products, which are highly similar, but not identical and not 'bioidentical', to approved 'reference' agents. ${ }^{2}$

CT-P13 is an immunoglobulin (Ig)G1 chimeric human-murine monoclonal antibody biosimilar to INX. CT-P13 is produced in the same type of cell-line (Sp2/0-AG14-purchased from ATCC, Cat. CRL-1581) and has an identical amino acid sequence to INX. CT-P13 and INX have demonstrated comparable in vitro primary pharmacodynamics (PD) in a range of studies (CELLTRION, Inc unpublished data; see online supplementary appendix A). CT-P13 and INX showed comparable binding affinities to monomeric and trimeric forms of human TNF $\alpha$ (hTNF $\alpha$ ), transgenic mouse hTNF $\alpha$ ( $\operatorname{tmhTNF} \alpha$ ) expressed by Jurkat cells and to $F c \gamma$ receptors and FcRn. Comparable hTNF $\alpha$ neutralising activity against a $\mathrm{TNF} \alpha$-sensitive mouse sarcoma cell-line (WEHI-164) has also been demonstrated. CT-P13 and INX are also comparable in terms of: lack of binding activity with hTNF $\beta$ and TNF $\alpha$ from a range of different species known not to bind infliximab; relative binding affinities to complement protein $\mathrm{C} 1 \mathrm{q}$; complement dependent cytotoxicity effects and apoptotic effects against a Jurkat $\mathrm{T}$ cell-line expressing tmhTNF $\alpha$. Comparable cytotoxic activities have been achieved as a result of antibody-dependent cellular cytotoxicity evaluation of human peripheral blood mononuclear cells against tmhTNF $\alpha$-Jurkat T cells, demonstrating biosimilarity of CT-P13 and INX. Highly comparable human tissue cross-reactivity results have been observed for biotinylated CT-P13 and biotinylated INX. CT-P13 was also assessed for bioequivalence to INX in a phase 1 trial in ankylosing spondylitis (AS). ${ }^{3}$ 
Based on the data described, this trial, PLANETRA (Programme evaluating the Autoimmune disease iNvEstigational drug cT-p13 in $R A$ patients), was conducted with the approval of the regulatory authorities including EMA. PLANETRA was designed to assess efficacy equivalence and to evaluate pharmacokinetics (PK), PD and overall safety of multiple doses of CT-P13 versus INX in active RA patients.

\section{PATIENTS AND METHODS}

Patients

Patients with active RA according to the revised 1987 American College of Rheumatology (ACR) classification criteria for $\geq 1$ year prior to screening were recruited. Patients had to have $\geq 6$ swollen and $\geq 6$ tender joints and at least two of the following: morning stiffness lasting $\geq 45 \mathrm{~min}$; serum $\mathrm{C}$ reactive protein (CRP) concentration $>2.0 \mathrm{mg} / \mathrm{dl}$ and erythrocyte sedimentation rate (ESR) $>28 \mathrm{~mm} / \mathrm{h}$ despite methotrexate (MTX) therapy for $\geq 3$ months (stable dose of $12.5-25 \mathrm{mg} /$ week for $\geq 4$ weeks prior to screening). Patients were permitted to receive both oral glucocorticoids (equivalent to $\leq 10 \mathrm{mg}$ daily prednisolone) and non-steroidal anti-inflammatory drugs, if they had received a stable dose for $\geq 4$ weeks prior to screening. Additional details of patient eligibility criteria are provided online (see online supplementary appendix B).

\section{Study design}

The study (ClinicalTrials.gov NCT01217086) was conducted according to the Declaration of Helsinki and the International Committee on Harmonisation good clinical practice. The protocol was reviewed and approved by regulatory authorities and the ethics committees of each study site. Written informed consent was obtained from all patients. The study was conducted at 100 centres across 19 countries in Europe, Asia, Latin America and Middle East.

Patients were randomly assigned $1: 1$ to receive $2 \mathrm{~h}$ intravenous infusion of either $3 \mathrm{mg} / \mathrm{kg}$ of CT-P13 (CELLTRION INC, Incheon, Republic of Korea) or INX (Janssen Biotech Inc, Horsham, Pennsylvania, USA) at weeks 0,2 and 6 and then

Table 1 Baseline demographics and disease characteristics*

\begin{tabular}{|c|c|c|c|}
\hline & $\begin{array}{c}\text { CT-P13 } \\
3 \mathrm{mg} / \mathrm{kg}(\mathrm{N}=302)\end{array}$ & $\begin{array}{c}\text { INX } \\
3 \mathrm{mg} / \mathrm{kg}(\mathrm{N}=304)\end{array}$ & Total $(\mathrm{N}=606)$ \\
\hline \multicolumn{4}{|l|}{ Age (years) } \\
\hline Median (range) & $50(18-75)$ & $50(21-74)$ & $50(18-75)$ \\
\hline \multicolumn{4}{|l|}{ Gender, no (\%) } \\
\hline Female & $245(81.1)$ & $256(84.2)$ & $501(82.7)$ \\
\hline Male & $57(18.9)$ & $48(15.8)$ & $105(17.3)$ \\
\hline \multicolumn{4}{|l|}{ Ethnicity, no (\%) } \\
\hline Asian & $34(11.3)$ & $37(12.2)$ & $71(11.7)$ \\
\hline Black & $2(0.7)$ & $1(0.3)$ & $3(0.5)$ \\
\hline White & $220(72.8)$ & $222(73.0)$ & $442(72.9)$ \\
\hline Other & $46(15.2)$ & $44(14.5)$ & $90(14.9)$ \\
\hline Height $(\mathrm{cm})$, median (range) & $162.3(144.0-186.0)$ & $162.0(124.0-190.0)$ & $162.0(124.0-190.0)$ \\
\hline Weight $(\mathrm{kg})$, median (range) & $69.0(36.5-134.0)$ & $68.0(36.0-136.0)$ & $68.6(36.0-136.0)$ \\
\hline BMI $\left(\mathrm{kg} / \mathrm{m}^{2}\right)$, median (range) & $26.3(13.9-49.8)$ & $25.4(15.0-53.1)$ & $25.9(13.9-53.1)$ \\
\hline Anti-CCP antibody-positive, no (\%) & $205(67.9)$ & $213(70.1)$ & $418(69.0)$ \\
\hline \multicolumn{4}{|l|}{ Joint count } \\
\hline TJC (68 joints) & $25.6(13.9)$ & $24.0(12.9)$ & $24.8(13.4)$ \\
\hline SJC (66 joints) & $16.2(8.7)$ & $15.2(8.3)$ & $15.7(8.5)$ \\
\hline TJC (28 joints) & $15.9(6.4)$ & $15.1(6.1)$ & $15.5(6.2)$ \\
\hline SJC (28 joints) & $12.0(4.9)$ & $11.2(4.7)$ & $11.6(4.8)$ \\
\hline Duration of prior MTX therapy (weeks) & $97.7(141.2)$ & $89.4(96.5)$ & $93.6(120.8)$ \\
\hline MTX dose (mg) & $15.6(3.1)$ & $15.6(3.2)$ & $15.6(3.1)$ \\
\hline CDAl & 40.9 (11.5) & $39.3(11.1)$ & $40.1(11.3)$ \\
\hline SDAI & $42.8(11.9)$ & $41.2(11.7)$ & $42.0(11.8)$ \\
\hline CRP (mg/dl) & $1.9(2.5)$ & $1.9(2.2)$ & $1.9(2.4)$ \\
\hline $\mathrm{ESR}(\mathrm{mm} / \mathrm{h})$ & $46.6(22.4)$ & $48.5(22.6)$ & $47.5(22.5)$ \\
\hline Anti-CCP (IU/ml) & $190.4(124.1)$ & $197.9(122.7)$ & $194.1(123.3)$ \\
\hline IgA RF (IU/ml) & $54.9(88.9)$ & $65.8(99.3)$ & $60.3(94.3)$ \\
\hline $\operatorname{lgM} \mathrm{RF}(\mathrm{IU} / \mathrm{ml})$ & $123.3(114.6)$ & $129.5(113.8)$ & $126.4(114.1)$ \\
\hline $\operatorname{lgG~RF}(I U / m l)$ & $68.4(89.4)$ & $66.2(85.4)$ & $67.3(87.3)$ \\
\hline DAS28-CRP & $5.9(0.8)$ & $5.8(0.9)$ & $5.8(0.9)$ \\
\hline HAQ & $1.6(0.6)$ & $1.6(0.6)$ & $1.6(0.6)$ \\
\hline Patient's assessment of pain & $65.9(17.4)$ & $65.5(17.2)$ & $65.7(17.3)$ \\
\hline Patient global assessment of disease activity & $65.7(17.2)$ & $65.4(17.0)$ & $65.5(17.1)$ \\
\hline Physician global assessment of disease activity & $64.7(14.3)$ & $65.0(13.5)$ & $64.8(13.9)$ \\
\hline
\end{tabular}


q8 weeks up to week 30 . Patients were premedicated with antihistamine (chlorpheniramine $2-4 \mathrm{mg}$ or dose of equivalent antihistamine) $30-60 \mathrm{~min}$ prior to the start of infusion at the investigator's discretion. Weekly MTX (12.5-25 mg/week, oral or parenteral dose) and folic acid ( $\geq 5 \mathrm{mg} /$ week, oral dose) were coadministered. Rescue therapy was only allowed with tramadol and/or acetaminophen. Salvage therapy was defined as an antirheumatoid drug, such as disease-modifying antirheumatic drugs, non-steroidal anti-inflammatory drugs and any biological agent for the treatment of RA, received on or after the day of the first dose of study treatment.

\section{Study endpoints}

The primary endpoint was to demonstrate equivalent efficacy of CT-P13 to INX at week 30, as determined by ACR20 response criteria. Equivalence of efficacy was concluded if the 95\% CIs for treatment difference were within $\pm 15 \%$ at week 30 .

Secondary endpoints included additional efficacy, immunogenicity, safety, PK and PD parameters. Clinical assessments of disease activity, including the additional measures: ACR individual component scores; ACR20/ACR50/ACR70; time-to-onset of ACR20; mean decrease in Disease Activity Score 28 (DAS28); European League Against Rheumatism (EULAR) response criteria; Clinical Disease Activity Index (CDAI); Simplified Disease Activity Index (SDAI) and general health status (Medical Outcomes Study Short-Form Health Survey (SF-36)), were performed before infusion at baseline, weeks 14 and 30. A post hoc analysis of ACR-EULAR remission rate at week 30 was also performed. ${ }^{4}$

Blood samples collected at screening and weeks 14 and 30 were assessed for antidrug antibodies (ADA), and a post hoc analysis of endpoints by ADA status was conducted.
Immunogenicity testing used both the CT-P13 tag and INX tag (see online supplementary appendix C). Antibodies against CT-P13 or INX were measured using an electrochemiluminescent immunoassay method using the Meso Scale Discovery platform (MSD, Rockville, Maryland, USA).

Safety endpoints included incidence and type of adverse events (AEs) and infection, serious AEs, incidence of infusionrelated reactions and changes from baseline in clinical laboratory parameters. AEs were coded using the Medical Dictionary for Regulatory Activities and severity was characterised as mild, moderate or severe.

All patients were screened for latent or active tuberculosis (TB) by an interferon $\gamma$-release assay using QuantiFERON-TB Gold in tube (QTF-TB Gold-IT, Cellestis, Australia) and chest $\mathrm{X}$-ray and monitored for any clinical signs and symptoms of TB at each planned visit. Patients with latent TB received prophylactic medication before and during the study period according to country-specific guidelines. For countries with an increased incidence of TB, QTF-TB Gold-IT was used at weeks 14 and 30 to identify positive conversion from negative results at baseline, according to WHO recommendations for sole use of interferon $\gamma$-release assay in non-HIV adults receiving anti-TNF therapy. 56

PK endpoints included $\mathrm{C}_{\max }, \mathrm{C}_{\min }, \mathrm{C}_{\mathrm{av}, \mathrm{ss}}$, peak to trough fluctuation ratio and time to reach $\mathrm{C}_{\max }\left(\mathrm{T}_{\max }\right)$. PD endpoints included concentrations of serum CRP, rheumatoid factor (RF) and anticyclic citrullinated peptide (anti-CCP) and ESR. Serum blood samples were obtained immediately before each dosing for PK and PD analyses, and at the end and $1 \mathrm{~h}$ after the end of each treatment infusion for PK analysis. All PK analyses were conducted using a flow-through immunoassay platform (GyrolabxP; Gyros AB, Sweden).

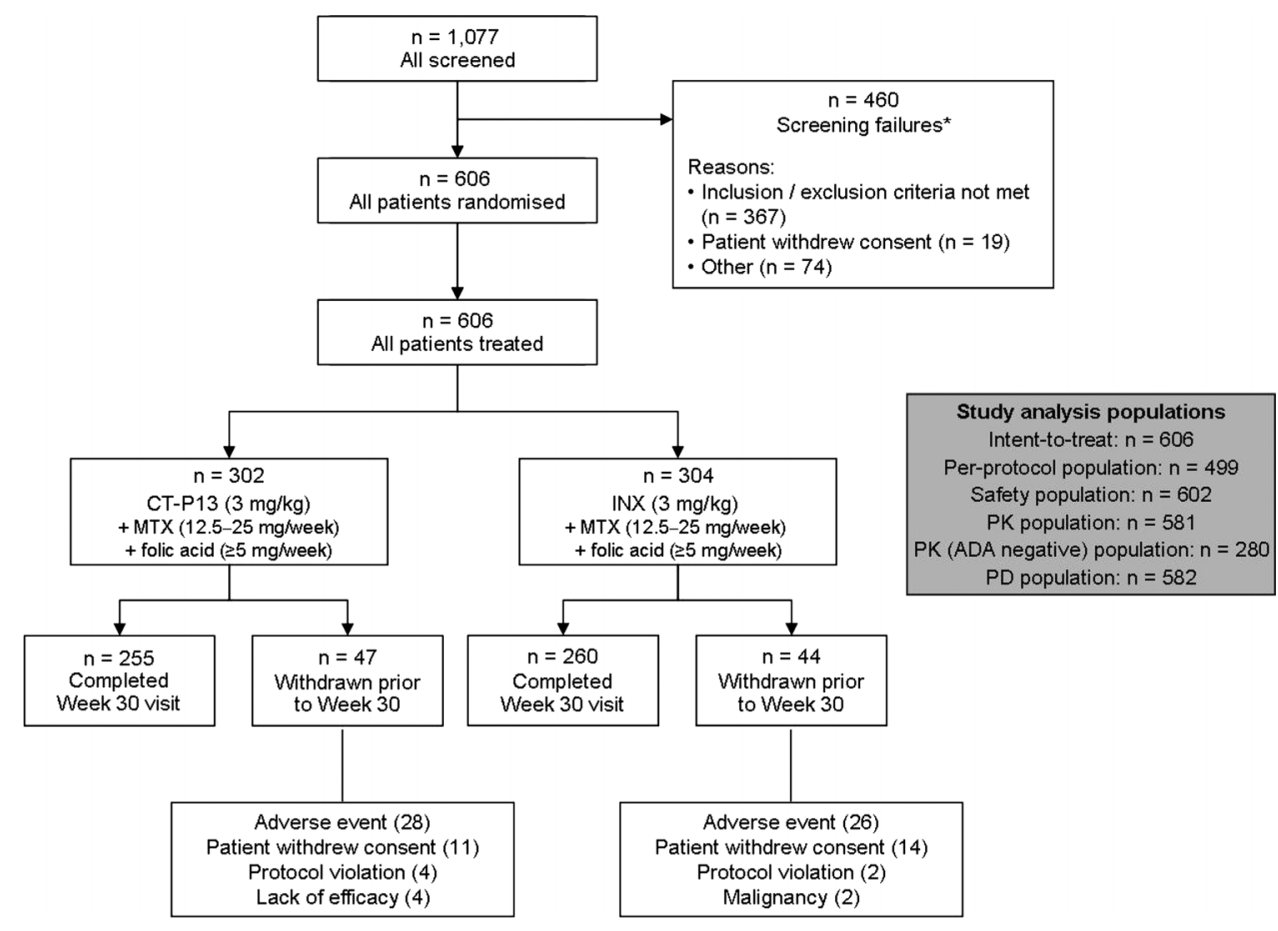

Figure 1 Flowchart of patient disposition. A total of 1077 patients were screened for the study, and 606 eligible patients were randomised into a CT-P13 group ( $\mathrm{N}=302)$ or an innovator infliximab (INX) group ( $\mathrm{N}=304)$ to receive $3 \mathrm{mg} / \mathrm{kg}$ of CT-P13 or INX, respectively, coadministered with methotrexate (MTX) and folic acid. All 606 randomly assigned patients were included in the intention-to-treat population. A total of 107 out of 606 randomised patients were excluded from the per-protocol population due to the various protocol violations. *Eleven patients from a potentially fraudulent study site were excluded from analyses. 


\section{Statistical analysis}

Sample size was determined using the following criterion: therapeutic equivalence to INX in the all randomised population was based on expected responder rates of $50 \%$ in the test and control groups. ${ }^{1}$ Specifying a two-sided $\alpha$ level of 0.05 , power of $80 \%$ and a two-sided equivalence margin of $15 \%$ required 468 patients in the per-protocol (PP) population final analysis. Assuming exclusion of $20 \%$ of patients from the PP population, this required a minimum of 584 randomised patients. In an equivalence trial, we conclude that two treatments are equivalent if the observable difference $\left(\Delta_{\mathrm{E}}\right)$ between them lies within an established interval for predefined clinical equivalence margin, $(-\mathrm{d}, \mathrm{d})$. The 'null hypothesis' is that the difference $\Delta_{\mathrm{E}}$ is outside of the equivalence margin, that is, either $\Delta_{\mathrm{E}}>\mathrm{d}$ or $\Delta_{\mathrm{E}}<-\mathrm{d}$. If collected data on the true difference $\Delta_{\mathrm{E}}$ reject the null hypothesis of 'non-equivalence' then we can accept the alternative explanation $\left(-\mathrm{d} \leq \Delta_{\mathrm{E}} \leq \mathrm{d}\right)$ that the two treatments work equally well.

All primary efficacy analyses were performed on both the intention-to-treat (ITT) and PP populations. All other efficacy analyses were performed on the PP population only. The proportion of patients achieving ACR20 response at week 30 was analysed by the exact binomial approach, calculating a point estimate and 95\% CIs for the difference in proportion between the two treatment groups. The equivalence margin within $\pm 15 \%$ at week 30 was selected based on recommendations from regulatory bodies ${ }^{89}$ and historical data from clinical trials of INX plus MTX in RA. ${ }^{10-13}$ A weighted average for the treatment difference in ACR20 response between the INX plus MTX and placebo plus MTX was nearly 30\%, and so the equivalence margin of $15 \%$ was considered appropriate.

A sensitivity analysis considering stratification factors was also performed, accounting for region (EU or non-EU) and serum CRP ( $\leq 2 \mathrm{mg} / \mathrm{dl}$ or $>2 \mathrm{mg} / \mathrm{dl}$ ). The exact binomial and sensitivity analyses were repeated for the secondary ACR response criteria. Time-to-onset of ACR20 response was analysed by survival analysis. Descriptive statistics for change from baseline were presented by randomised treatment group and study visit for DAS28, EULAR response, SDAI, CDAI and SF-36 subscales.

An analysis of covariance for DAS28 was performed with treatment group as a fixed effect and baseline DAS28 score, region and CRP as covariates. A point estimate and 95\% CI for the treatment difference were provided. The EULAR response criteria were analysed using a relative risk (RR) with 95\% CI for the difference in response between the two treatment groups. The number of patients requiring salvage retreatment was summarised by randomised treatment group and visit.

Safety endpoints analysed in safety population consisted of all patients who received at least one (full or partial) dose of either of the study treatments during any dosing period. In this population, patients were included in the CT-P13 group for safety analyses, irrespective of their randomisation if they received at least one (full or partial) dose of CT-P13.

The PK-PD population consisted of all patients who received either CT-P13 or INX during the 30-week blinded study period and had at least one PK-PD concentration data value. PK-PD parameters were summarised using quantitative descriptive statistics by actual treatment group and study visit.

\section{RESULTS}

Patients

The first patient was screened in November 2010; the last week 30 evaluation was performed in November 2011. Baseline demographics and disease status were comparable between treatment groups (table 1). Of the 606 randomised patients, 515 completed the 30 -week study period and, of these, 16 patients were excluded from the PP population due to major protocol violations. Discontinuation in randomised patients was primarily due to AEs (8.9\%) and patient withdrawal of consent $(4.1 \%)$ (figure 1).

\section{Efficacy}

The primary endpoint, ACR20 response at week 30, was equivalent between treatment groups and achieved in $60.9 \%$ and $58.6 \%$ in ITT $(n=606,95 \%$ CI $-6 \%$ to $10 \%)$ and $73.4 \%$
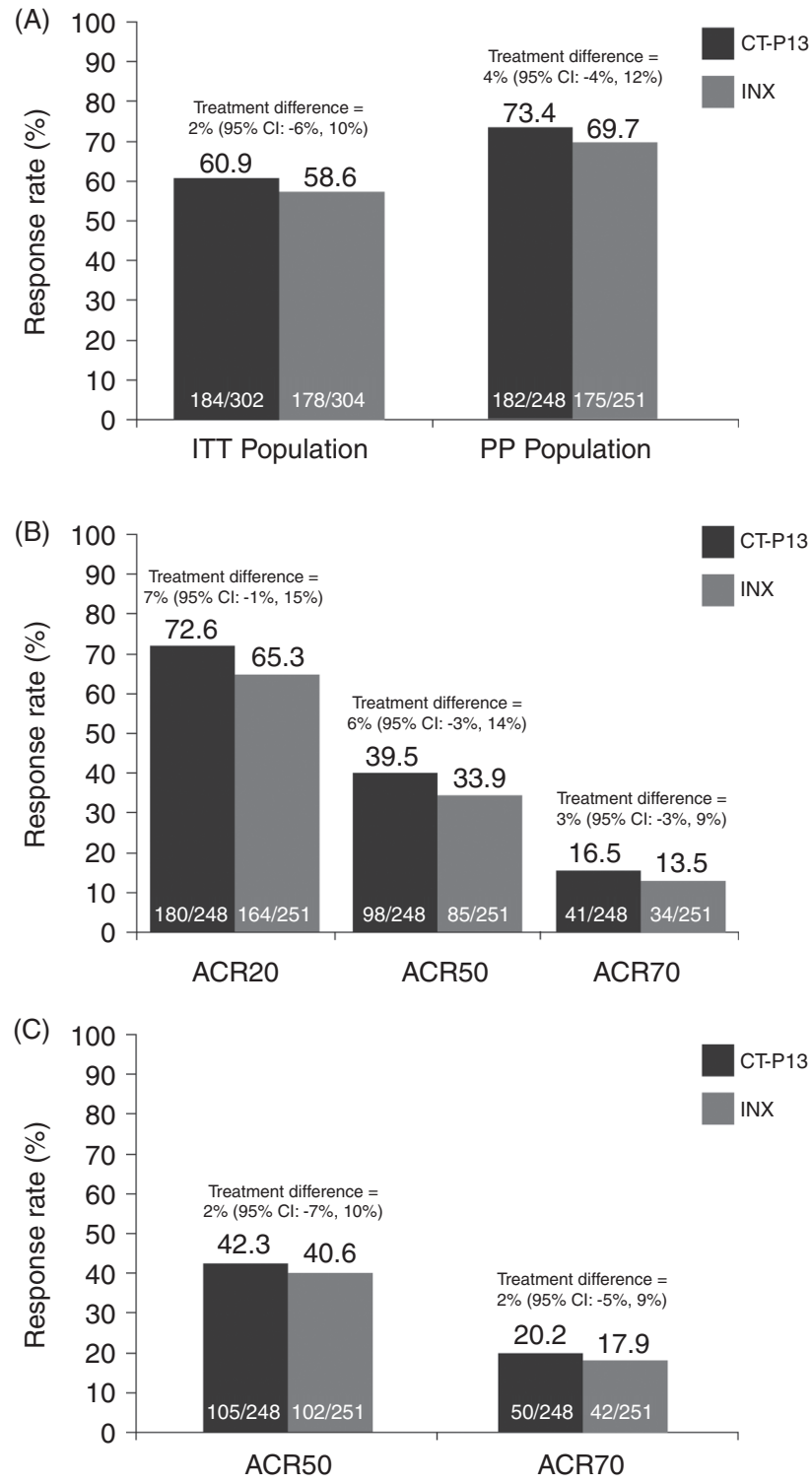

Figure 2 American College of Rheumatology (ACR) response rates. (A) ACR20 improvement criteria at week 30 (primary efficacy endpoint) for the intention-to-treat (ITT) (N=302 and 304 in CT-P13 and innovator infliximab (INX) groups, respectively) and per-protocol (PP) populations ( $\mathrm{N}=248$ and 251 patients in CT-P13 and INX groups, respectively). (B) ACR20, ACR50 or ACR70 improvement criteria at week 14 for the PP population. (C) ACR50 or ACR70 improvement criteria at week 30 for the PP population. ACR20, ACR50 and ACR70 are the ACR $20 \%, 50 \%$ and $70 \%$ improvement criteria, respectively. $95 \% \mathrm{Cl}$ was calculated by the exact binomial method. 
Table 2 Mean changes of secondary outcome measures from baseline

\begin{tabular}{|c|c|c|c|c|}
\hline Secondary outcome measure, mean (SD) & Timepoint & $\begin{array}{l}\text { CT-P13 } \\
3 \mathrm{mg} / \mathrm{kg}\end{array}$ & $\begin{array}{c}\text { INX } \\
3 \mathrm{mg} / \mathrm{kg}\end{array}$ & p Value* \\
\hline TJC (68 joints) & $\begin{array}{l}\text { Week } 14 \\
\text { Week } 30\end{array}$ & $\begin{array}{l}-14.6(11.1) \\
-16.5(11.7)\end{array}$ & $\begin{array}{l}-14.0(11.4) \\
-15.7(12.6)\end{array}$ & $\begin{array}{l}0.559 \\
0.458\end{array}$ \\
\hline SJC (66 joints) & $\begin{array}{l}\text { Week } 14 \\
\text { Week } 30\end{array}$ & $\begin{array}{l}-10.9(8.1) \\
-12.4(8.9)\end{array}$ & $\begin{array}{l}-10.2(8.0) \\
-11.4(9.1)\end{array}$ & $\begin{array}{l}0.331 \\
0.219\end{array}$ \\
\hline TJC (28 joints) & $\begin{array}{l}\text { Week } 14 \\
\text { Week } 30\end{array}$ & $\begin{array}{r}-9.2(6.4) \\
-10.1(6.7)\end{array}$ & $\begin{array}{l}-8.4(6.0) \\
-9.5(6.4)\end{array}$ & $\begin{array}{l}0.149 \\
0.378\end{array}$ \\
\hline SJC (28 joints) & $\begin{array}{l}\text { Week } 14 \\
\text { Week } 30\end{array}$ & $\begin{array}{l}-7.8(5.1) \\
-8.8(5.3)\end{array}$ & $\begin{array}{l}-7.2(5.0) \\
-7.9(5.6)\end{array}$ & $\begin{array}{l}0.173 \\
0.073\end{array}$ \\
\hline CDAI & $\begin{array}{l}\text { Week } 14 \\
\text { Week } 30\end{array}$ & $\begin{array}{l}-23.5(12.4) \\
-25.2(13.3)\end{array}$ & $\begin{array}{l}-21.6(11.6) \\
-23.6(13.0)\end{array}$ & $\begin{array}{l}0.076 \\
0.182\end{array}$ \\
\hline SDAl & $\begin{array}{l}\text { Week } 14 \\
\text { Week } 30\end{array}$ & $\begin{array}{l}-24.0(13.0) \\
-25.8(14.0)\end{array}$ & $\begin{array}{l}-22.4(11.9) \\
-24.4(13.6)\end{array}$ & $\begin{array}{l}0.141 \\
0.247\end{array}$ \\
\hline SF-36 & $\begin{array}{l}\text { Week } 14 \\
\text { Physical component summary } \\
\text { Mental component summary } \\
\text { Week } 30 \\
\text { Physical component summary } \\
\text { Mental component summary }\end{array}$ & $\begin{array}{l}7.5(7.1) \\
6.6(10.2) \\
7.1(7.9) \\
7.1(10.0)\end{array}$ & $\begin{array}{l}5.8(6.8) \\
6.5(10.4) \\
6.5(7.6) \\
6.6(10.4)\end{array}$ & $\begin{array}{l}0.007 \\
0.925 \\
0.372 \\
0.561\end{array}$ \\
\hline CRP & $\begin{array}{l}\text { Week } 14 \\
\text { Week } 30\end{array}$ & $\begin{array}{l}-0.6(2.5) \\
-0.6(2.0)\end{array}$ & $\begin{array}{l}-0.8(1.9) \\
-0.8(1.9)\end{array}$ & $\begin{array}{l}0.413 \\
0.323\end{array}$ \\
\hline HAQ & $\begin{array}{l}\text { Week } 14 \\
\text { Week } 30\end{array}$ & $\begin{array}{l}-0.6(0.6) \\
-0.6(0.6)\end{array}$ & $\begin{array}{l}-0.5(0.5) \\
-0.5(0.6)\end{array}$ & $\begin{array}{l}0.053 \\
0.082\end{array}$ \\
\hline Patient's assessment of pain & $\begin{array}{l}\text { Week } 14 \\
\text { Week } 30\end{array}$ & $\begin{array}{l}-29.5(23.2) \\
-29.5(25.5)\end{array}$ & $\begin{array}{l}-27.2(23.2) \\
-27.8(24.9)\end{array}$ & $\begin{array}{l}0.253 \\
0.443\end{array}$ \\
\hline Patient global assessment of disease activity & $\begin{array}{l}\text { Week } 14 \\
\text { Week } 30\end{array}$ & $\begin{array}{l}-29.5(22.1) \\
-28.1(25.9)\end{array}$ & $\begin{array}{l}-25.5(24.4) \\
-27.0(25.6)\end{array}$ & $\begin{array}{l}0.057 \\
0.658\end{array}$ \\
\hline Physician global assessment of disease activity & $\begin{array}{l}\text { Week } 14 \\
\text { Week } 30\end{array}$ & $\begin{array}{l}-35.4(19.3) \\
-35.6(20.6)\end{array}$ & $\begin{array}{l}-33.7(19.5) \\
-35.3(21.2)\end{array}$ & $\begin{array}{l}0.314 \\
0.910\end{array}$ \\
\hline
\end{tabular}

and $69.7 \%$ in PP population $(n=499,95 \%$ CI $-4 \%$ to $12 \%)$ for CT-P13 and INX, respectively (figure 2A).

Equivalent results were also shown for ACR responses in the PP population at weeks 14 and 30 (figure 2B,C) for CT-P13 and INX, respectively. ACR50 and 70 responses in the ITT population at week 30 were comparable $(35.1 \%$ and $16.6 \%$ vs $34.2 \%$ and $15.5 \%$ for CT-P13 and INX, respectively). Post hoc analysis by baseline CRP demonstrated highly similar ACR20 responses in the ITT population for CT-P13 and INX, respectively (CRP $>2 \mathrm{mg} / \mathrm{dl}$ : $58.7 \%$ and $58.6 \%$; $\leq 2 \mathrm{mg} / \mathrm{dl}: 61.9 \%$ and $58.5 \%$ ).

Mean improvements from baseline for additional secondary efficacy endpoints including CDAI and SDAI (CT-P13 (25.2 and 25.8) vs INX (23.6 and 24.4) at week 30, respectively) were equivalent at weeks 14 and 30 between treatment groups (table 2). The proportion in each group achieving good or moderate EULAR responses (CRP) at week 30 was highly similar (CT-P13 85.8\%; INX 87.1\%, RR=0.98, 95\% CI 0.92 to 1.06 ). Low disease activity or remission according to DAS28-CRP was achieved in $40.9 \%$ and $39.0 \%$ with CT-P13 and INX, respectively (figure 3). The proportion of patients requiring salvage therapy at week 30 was also highly similar between CT-P13 (3.2\%) versus INX (4.0\%). The medians of time-to-onset of ACR20 of the two treatment groups were almost identical (median CT-P13, 99 days; INX, 100 days).

In addition, ACR/EULAR remission rates were comparable for CT-P13 and INX at week 30 (Boolean: 6.9\% (17/248) and 6.8\% (17/251); SDAI: 9.7\% (24/248) and 9.6\% (24/251)). Efficacy criteria were also analysed according to ADA status at week 30 (see online supplementary appendix D).
Overall, no statistically significant differences in responses between the two treatment groups were found.

\section{Immunogenicity}

Antibodies to infliximab were detected using INX tag in $25.4 \%$ $(n=69)$ and $25.8 \%(n=70)$ of patients for CT-P13 and INX at week 14 and $48.4 \%(n=122)$ and $48.2 \%(n=122)$ of patients for CT-P13 and INX, respectively, at week 30.

\section{Safety}

Overall treatment-emergent AEs (TEAEs) were reported in 181 (60.1\%) patients and $183(60.8 \%)$ patients for CT-P13 and INX, respectively. TEAEs considered related to study treatment were reported in 106 (35.2\%) and 108 (35.9\%) patients for CT-P13 and INX, respectively (table 3 ). The majority of TEAEs were mild-to-moderate in intensity. The TEAEs considered by the investigator to be related to the study treatment and most frequently reported for patients were-CT-P13: latent TB (positive conversion of QTF, $n=13)$, increased ALT $(n=12)$, increased AST $(n=8)$ and a flare of RA activity $(n=7)$; INX: latent TB $(n=14)$, increased ALT $(n=11)$, increased AST $(n=8)$ and urinary tract infection $(n=7)$. Two patients were withdrawn due to malignancies in the INX group (figure 1), breast cancer and cervix carcinoma.

Patients with latent TB were recommended for prophylactic TB medication, and latent TB in patients receiving prophylactic TB medication did not convert to active TB. There were three cases of active TB in the CT-P13 group and none in the INX group (see online supplementary appendix E). 
(A)
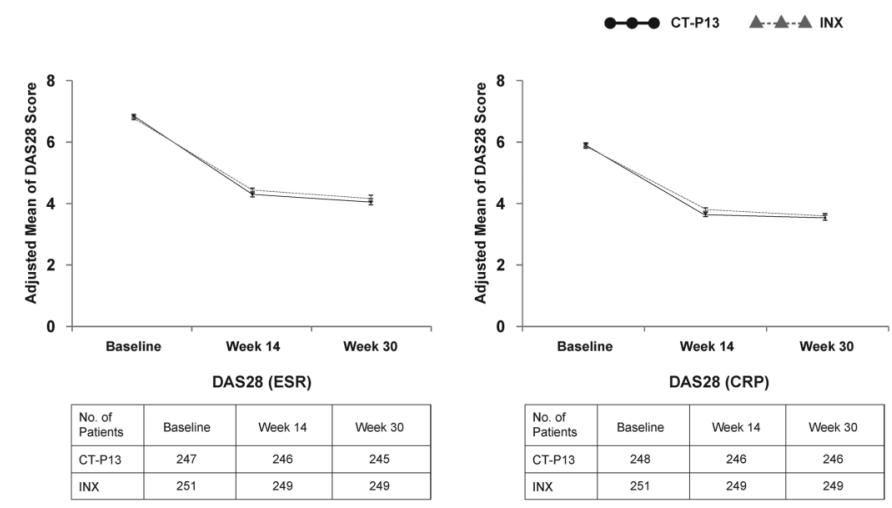

(B) EULAR (ESR)

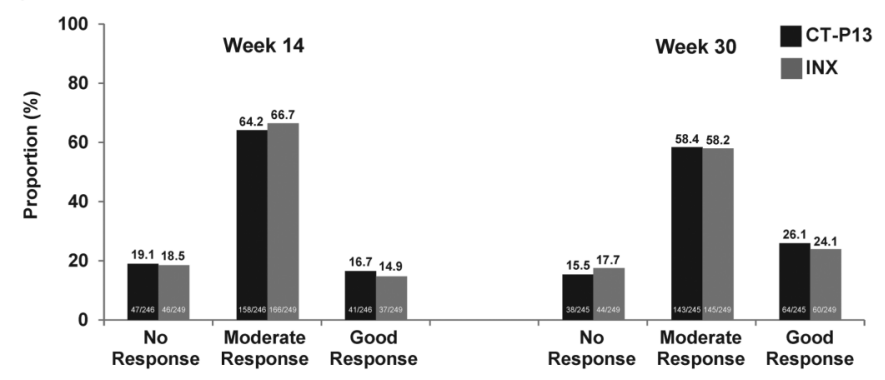

(C) DAS28 (ESR)

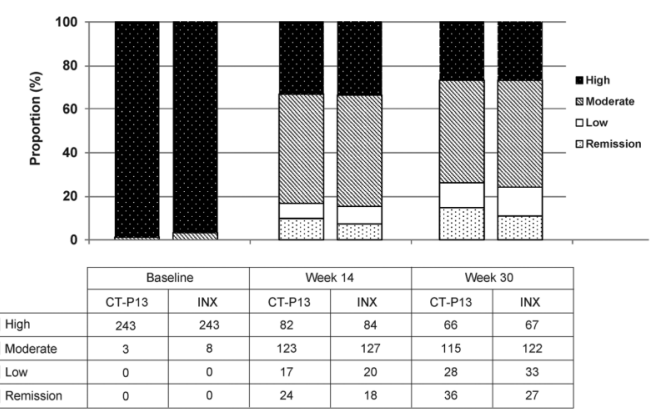

DAS28 (CRP)
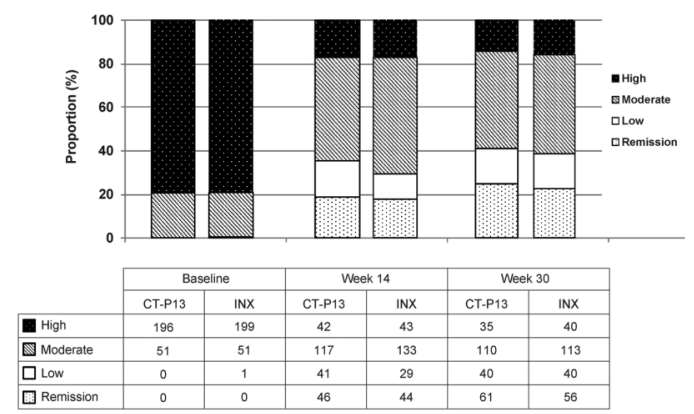

EULAR (CRP)

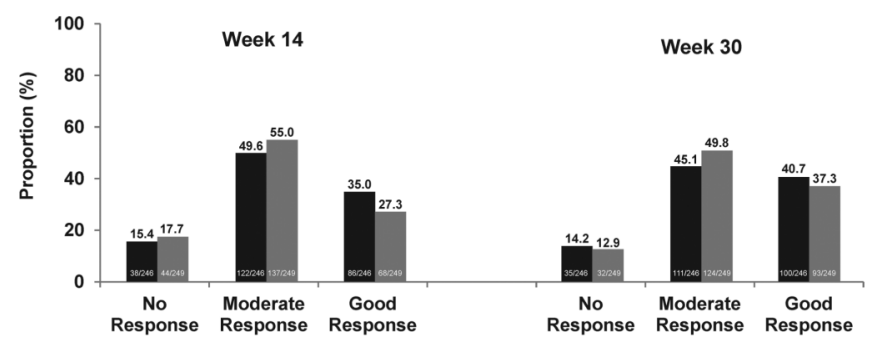

Figure 3 Changes over time in the Disease Activity Score in 28 joints (DAS28) and European League Against Rheumatism (EULAR) responses for CT-P13 (3 mg/kg) and innovator infliximab (INX) (3 mg/kg) treatment in the per-protocol population. (A) Adjusted mean DAS28 score based on erythrocyte sedimentation rate (ESR) and C reactive protein (CRP) at baseline, weeks 14 and 30. Error bars represent SE. (B) EULAR response criteria based on DAS28 score at weeks 14 and 30 following treatment. (C) Disease activity based on DAS28 (ESR) and DAS28 (CRP) at baseline, weeks 14 and 30 .

Infusion-related reactions occurred in $20(6.6 \%)$ and 25 (8.3\%) patients for CT-P13 and INX, respectively. The proportions of infusion-related reactions for CT-P13 and INX groups were $6.7 \%(\mathrm{n}=9)$ versus $13.3 \%(\mathrm{n}=18)$ in ADA-positive group and $4.2 \%(\mathrm{n}=6)$ versus $2.8 \%(\mathrm{n}=4)$ in ADA-negative group, respectively. Serious TEAEs were reported in $30(10.0 \%)$ and $21(7.0 \%)$ patients for CT-P13 and INX, respectively (see online supplementary appendix F). There were no deaths reported during the study.

\section{Pharmacokinetics and pharmacodynamics}

The PK and PD endpoint results were highly similar for each treatment group. In the PK population, geometric means and peak serum concentrations $\left(\mathrm{C}_{\max }\right)$ were highly similar after each infusion of study treatment for doses $1-6$, as was the overall range of geometric means across all doses (CT-P13, range 83.9-111.9 $\mu \mathrm{g} / \mathrm{ml}$; INX, range 83.8$105.1 \mu \mathrm{g} / \mathrm{ml}$ ). The mean secondary PK endpoints were highly similar for CT-P13 and INX (see online supplementary appendix G).

In the ADA-negative subset, geometric mean $\mathrm{C}_{\max }$ values were 96.7 and $91.6 \mu \mathrm{g} / \mathrm{ml}(90 \% \mathrm{CI}$ of ratio $97 \%$ to $115 \%)$, and
$\mathrm{C}_{\min }$ values were 1.9 and $1.8 \mu \mathrm{g} / \mathrm{ml}(90 \% \mathrm{CI}$ of ratio $85 \%$ to $132 \%)$ for CT-P13 and INX at dose 5, respectively. In the ADA-positive subset, geometric mean $\mathrm{C}_{\max }$ values were 85.1 and $76.7 \mu \mathrm{g} / \mathrm{ml}(90 \% \mathrm{CI}$ of ratio $99 \%$ to $124 \%)$, and $\mathrm{C}_{\min }$ values were 0.6 and $0.6 \mu \mathrm{g} / \mathrm{ml}(90 \%$ CI of ratio $82 \%$ to $107 \%)$ for CT-P13 and INX at dose 5 , respectively.

CT-P13 and INX had comparable mean CRP $(1.2$ vs $1.1 \mathrm{mg} / \mathrm{dl}$ and 1.1 vs $1.0 \mathrm{mg} / \mathrm{dl}$ ), ESR $(32.8$ vs $31.0 \mathrm{~mm} / \mathrm{h}$ and 30.6 vs $32.1 \mathrm{~mm} / \mathrm{h}$ ), anti-CCP (186.5 vs $195.4 \mathrm{IU} / \mathrm{ml}$ and 189.8 vs $174.6 \mathrm{IU} /$ $\mathrm{ml}$ ), IgA RF (41.2 vs $45.8 \mathrm{IU} / \mathrm{ml}$ and 33.9 vs $38.3 \mathrm{IU} / \mathrm{ml}$ ), IgG RF $(40.5 \mathrm{vs} 33.4 \mathrm{IU} / \mathrm{ml}$ and $33.5 \mathrm{vs} 29.5 \mathrm{IU} / \mathrm{ml}$ ) and IgM RF (90.0 vs $88.0 \mathrm{IU} / \mathrm{ml}$ and $83.9 \mathrm{vs} 82.5 \mathrm{IU} / \mathrm{ml}$ ) at weeks 14 and 30, respectively.

\section{DISCUSSION}

In this randomised, double-blind, multicentre, multinational, parallel-group, prospective PLANETRA study, we assessed the equivalence of efficacy and comparability of safety, PK and PD of multiple doses of CT-P13 $(3 \mathrm{mg} / \mathrm{kg})$ versus INX $(3 \mathrm{mg} / \mathrm{kg})$ administered up to week 30 in active RA patients with inadequate response to MTX treatment. Equivalence of efficacy was 
Table 3 Treatment-emergent adverse events (TEAEs) reported as related in at least $1 \%$ of patients in either treatment group, no (\%)

\begin{tabular}{|c|c|c|c|}
\hline $\begin{array}{l}\text { Related TEAEs reported in at least } \\
1 \% \text { of patients in either treatment } \\
\text { group }\end{array}$ & $\begin{array}{l}\text { CT-P13 } \\
3 \mathrm{mg} / \mathrm{kg} \\
(\mathrm{N}=301)^{*}\end{array}$ & $\begin{array}{l}\text { INX } \\
3 \mathrm{mg} / \mathrm{kg} \\
(\mathrm{N}=301)^{*}\end{array}$ & $\begin{array}{l}\text { Total } \\
(\mathrm{N}=602)\end{array}$ \\
\hline Alanine aminotransferase increased & $12(4.0)$ & $11(3.7)$ & $23(3.8)$ \\
\hline Aspartate aminotransferase increased & $8(2.7)$ & $8(2.7)$ & $16(2.7)$ \\
\hline$\gamma$-Glutamyltransferase increased & $2(0.7)$ & $3(1.0)$ & $5(0.8)$ \\
\hline Latent tuberculosis & $13(4.3)$ & $14(4.7)$ & $27(4.5)$ \\
\hline Upper respiratory tract infection & $4(1.3)$ & $4(1.3)$ & $8(1.3)$ \\
\hline Urinary tract infection & $4(1.3)$ & $7(2.3)$ & $11(1.8)$ \\
\hline Bronchitis & $4(1.3)$ & $4(1.3)$ & $8(1.3)$ \\
\hline Nasopharyngitis & $6(2.0)$ & $4(1.3)$ & $10(1.7)$ \\
\hline Gastroenteritis & $2(0.7)$ & $3(1.0)$ & $5(0.8)$ \\
\hline Herpes zoster & $1(0.3)$ & $3(1.0)$ & $4(0.7)$ \\
\hline Rhinitis & 0 & $3(1.0)$ & $3(0.5)$ \\
\hline Tuberculosis & $3(1.0)$ & 0 & $3(0.5)$ \\
\hline Infusion-related reaction & $20(6.6)$ & $25(8.3)$ & $45(7.5)$ \\
\hline Anaemia & $2(0.7)$ & $3(1.0)$ & $5(0.8)$ \\
\hline Neutropenia & $3(1.0)$ & $2(0.7)$ & $5(0.8)$ \\
\hline Leucopenia & $1(0.3)$ & $3(1.0)$ & $4(0.7)$ \\
\hline Headache & $4(1.3)$ & $6(2.0)$ & $10(1.7)$ \\
\hline Pyrexia & 0 & $3(1.0)$ & $4(0.7)$ \\
\hline Rash & $1(0.3)$ & $4(1.3)$ & $5(0.8)$ \\
\hline Nausea & $1(0.3)$ & $3(1.0)$ & $4(0.7)$ \\
\hline Flare in RA activity & $7(2.3)$ & $4(1.3)$ & $11(1.8)$ \\
\hline Bone pain & $3(1.0)$ & 0 & $6(1.0)$ \\
\hline Hypertension & $5(1.7)$ & $3(1.0)$ & $8(1.3)$ \\
\hline
\end{tabular}

demonstrated, and there was no clinically meaningful difference in safety data. Only comparability of PK data was shown in this study, as coadministration of MTX could affect PK data; PK bioequivalence has been assessed in a phase I study for ankylosing spondylitis patients in the absence of MTX. ${ }^{3}$

The primary outcome, ACR20 response at week 30, was shown to be equivalent for CT-P13 and INX: the 95\% CIs for treatment difference were within the predefined margins for equivalence of $\pm 15 \%$. To ensure a credible comparison with existing INX data, the disease definition for enrolment in our study was identical to ATTRACT ${ }^{1}$ and a separate phase III trial of INX in RA, ${ }^{12}$ and was similar to a further, more recent trial. ${ }^{13}$ The finding that baseline CRP levels in the equivalent INX arm of the ATTRACT study ( $3 \mathrm{mg} / \mathrm{kg}$, every 8 weeks) were higher than in both groups of this study (3.1 vs $1.9 \mathrm{mg} / \mathrm{dl})$, raising the possibility that our study had enrolled a population with less severe disease, led us to conduct a post hoc sensitivity analysis of patients with baseline CRP $>2$ or $\leq 2 \mathrm{mg} / \mathrm{dl}$. This analysis demonstrated that responses by baseline CRP level were highly similar between treatment groups regardless of baseline CRP level. The ACR responses observed in this study were higher than those reported at week 30 in ATTRACT (ACR20, 50 and $70: 60.9 \%, 35.1 \%$ and $16.6 \%$ for CT-P13 and $58.6 \%$, $34.2 \%$ and $15.5 \%$ for INX, respectively, vs $50 \%, 27 \%$ and $8 \%$ for INX in ATTRACT ${ }^{1}$ ). However, they were similar to INX responses in the START study (ACR20, 50 and 70 at week 30: $58.0 \%, 32.1 \%$ and 14.0\%), which included similar baseline tender joint count, swollen joint count and CRP. ${ }^{13}$
It is also interesting to note that although CRP is regarded as the better marker of inflammation, ESR may have utility in reflecting disease severity. ${ }^{14}{ }^{15}$ However, as ESR data are not available for ATTRACT or any other placebo-controlled INX plus MTX studies in the literature, we rely on assessment of CRP to ensure appropriate comparison of patient populations.

Although the point estimates of medians for time-to-onset of ACR20 were very similar, we have observed faster tendency of ACR 20 response among CT-P13 group compared with the INX group based on log-rank test result $(p=0.02)$. ACR20 responses were measured only at weeks 14 and 30; therefore, we have a limitation to adapt statistical survival methods on a very small number of evaluation time points and conclude log-rank test results from our data.

Efficacy criteria were also analysed according to ADA status at week 30 , and no statistically significant difference in responses between the two treatment groups was found. However, as this was a post hoc analysis, interpretation of these results should be done with care and to a limited extent.

In our study, PK and PD endpoint results were highly similar for each treatment group and antibody status had a minimal effect on the PK of infliximab. A difference was noted in the change from baseline in anti-CCP at week 30 and IgG RF at week 14. However, these two parameters are more indicative of disease severity rather than a direct marker of anti-TNF $\alpha$ effect. In addition, it should be noted that the assumptions of normality and homogeneity of variance were assessed for each parameter for the ANCOVA analysis. Both assumptions did not hold for anti-CCP, IgA RF, IgG RF and IgM RF, and valid conclusions for these parameters beyond investigating trends cannot be drawn.

The objective with regard to safety was to demonstrate comparability of CT-P13 and INX, not equivalence. Overall, CT-P13 was well tolerated, and its safety profile was comparable with INX. The rate of infusion reactions in both treatment groups was approximately $7.5 \%$, lower than the $20 \%$ incidence listed in the INX product information, although the incidence of severe infusion reactions was $1.3 \%$, slightly higher than the $<1 \%$ listed. ${ }^{16}$ The safety results were similar to those observed in the ATTRACT and ASPIRE trials. ${ }^{11}$ The incidence of active TB in patients receiving INX or CT-P13 in this study $(0 \%$ and $1.0 \%$, respectively) was similar to that described in ATTRACT $(0.3 \%)$ and ASPIRE $(0.5 \%)^{1}{ }^{17}$ and was not considered significant, as $42 \%$ of patients in our study were from countries listed in WHO Global tuberculosis report as having higher TB incidence, ${ }^{18}$ whereas ATTRACT and ASPIRE included only centres in North America and Western Europe. ${ }^{1} 17$

Immunogenicity testing demonstrated a comparable profile for CT-P13 and INX in terms of proportion of ADA-positive patients at weeks 14 and 30. Although the proportion of ADA-positive patients was slightly higher than that observed in previous studies, ${ }^{1}$ the method used to detect immunogenicity was more sensitive than those previously used, and the proportion of ADA-positive patients was similar to that observed in more recent studies of INX. ${ }^{19} 20$

Assessment of efficacy and safety of CT-P13 in patients with RA for up to 1 year is ongoing, and the positive results of this study provide a rationale for future studies of CT-P13 in the treatment of other TNF-mediated inflammatory diseases.

\section{CONCLUSIONS}

CT-P13 and INX were shown to be equivalent in terms of ACR20 response at week 30 in active RA patients with inadequate response to MTX treatment. Overall, CT-P13 was well tolerated and the safety profile of CT-P13 was comparable with that of INX. 


\section{Author affiliations}

'Division of Rheumatology, Hanyang University Hospital for Rheumatic Diseases, Seoul, Republic of Korea

${ }^{2}$ Department of Rheumatology and Clinical Immunology, Poznan University of Medical Sciences, Poznan, Poland

${ }^{3}$ Rheumatology Department, Centro de Estudios Reumatologicos, Santiago, Chile ${ }^{4}$ Department of Internal Medicine, Brokenshire Memorial Hospital, Davao City, Philippines

${ }^{5}$ Reumed, Lublin, Poland

${ }^{6}$ Scientific and Research Institute of Invalid Rehabilitation of MoH of Ukraine, Kiev, Ukraine

${ }^{7}$ Section of Non-coronarogenic Myocardial Diseases and Clinical Rheumatology، National Scientific Center, Kiev, Ukraine

${ }^{8}$ Department of Rheumatology and Clinical Immunology, Clinic of Internal Diseases, Clinical Center Banja Luka, Banja Luka, Bosnia and Herzegovina

${ }^{9}$ Centro Integral de Reumatologia del Caribe, Barranquilla, Colombia

${ }^{10}$ Rheumatology Department, Antiguo Hospital Civil de Guadalajara, Guadalajara, Mexico

${ }^{11}$ Rheumatology Department, Hospital Maria Auxiliadora, Lima, Peru

${ }^{12}$ Department of Medicine, Medical Center Manila, Manila, Philippines

${ }^{13}$ Rheumatology Department, Centro de Estudios Investigaciones Clinicas, Viña del Mar, Chile

${ }^{14}$ Rheuma Zentrum Favoriten, Vienna, Austria

${ }^{15}$ Division of Biostatistics, Department of Internal Medicine, University of New Mexico, Albuquerque, New Mexico, USA

${ }^{16}$ Clinical Planning and Medical Affairs Department, CELLTRION Inc, Incheon, Republic of Korea

${ }^{17}$ Division of Rheumatology, Department of Internal Medicine, Inha University Hospital, Incheon, Republic of Korea

${ }^{18}$ Department of Rheumatology and Clinical Immunology, Justus-Liebig University Giessen, Kerchoff-Klinik GmbH, Bad Nauheim, Germany

Acknowledgements The authors wish to thank the patients and study personnel who made this trial possible and the PLANETRA study investigators—Bosnia: Mulic Bacic S; Bulgaria: Bichovska D, Kadinov V, Oparanov B, Rashkov R, Toncheva A; Chile: Aguirre V, Arriagada Herrera M, Barria Negron L, Goecke Sariego I; Colombia: Chalem M, Diaz Cortez M, Otero Escalante WJ, Ruiz Santacruz O, Tobias Arteaga E; Italy: Bianchi G, Cutolo M, Salvarani C; Jordan: Alawneh K; Latvia: Andersone D, Saleniece S, Saulite-Kandevica D; Lithuania: Baranauskaite A, Bukauskiene L, Kausiene R, Smilgiene V, Stropuviene S; Mexico: Abud-Mendoza C, Araiza R, Cardona Cabrera R, Cons Molina F, Diaz Jimenez A, Morales-Torres J, Pacheco-Tena C, Xibille D; Peru: Calvo A, Castaneda Jimenez M, Chalouhi El-Khouri E, Chavez Corrales J, Vidal Neira L; Philippines: Amante EJ, Baes R, Eullaran R, Lanzon A, Lucero A Jr, Navarra S, Salido E, Tan P; Poland: Brzezicki J, Brzosko M, Daniluk S, Jaworkki J, Klimiuk P, Krogulek M, Racewicz A, Ruzga Z, Wiland P; Portugal: Vaz Patto J: Romania: Bojinca VC, Chicea LM, Cristei D, lanuli-Arvunescu MA, Motoc D, Pavel M, Rednic S; Slovakia: Jancovic R, Krpciar M, Zlnay D; Spain: Blanco Garcia F, Fernández-Nebró A, Gómez Centeno A, Martín-Mola E, Ucar Angulo E; UK: Adebajo A, Byrne P; Ukraine: Amosova K, Dzyak G, Gnylorybov A, Gyrina O, Hospodarskyy I, Polyvoda S, Smiyan S, Yagensky A, Yatsyshyn R; USA: Ahn C. Editorial support (writing assistance, assembling tables and figures, collating author comments, grammatical editing and referencing) was provided by Vanessa Lane, Peter Hopkins and Rory Elsome (TVF BioLogic, London, UK) and was funded by CELLTRION Inc, Incheon, Republic of Korea.

Contributors DHY, SJL and HUK were involved in the conception and design of the study, acquisition of data and/or analysis and interpretation of data; drafting of manuscript and revising it critically for important intellectual content; final approval of the version to be published. WP and UM-L were involved in the conception and design of the study; drafting of manuscript and revising it critically for important intellectual content; final approval of the version to be published. PH, PM, ER, MP, SS, $V K, N P, M A-B, S G-U, L M-O, M T, R J$ and $O Z$ were involved in the acquisition of data; drafting of manuscript and revising it critically for important intellectual content; final approval of the version to be published. The project management, clinical and medical monitoring, pharmacovigilance (PVG), data management, analysis of pharmacokinetic (PK) data, biostatistical analysis, and medical writing were performed under contract with PPD, Inc. in collaboration with the CELLTRION, Inc.

Funding This study was funded by CELLTRION Inc.

Competing interests All authors have completed the Unified Competing Interests form at http://www.icmje.org/coi_disclosure.pdf (available on request from the corresponding author) and declare: financial support for the submitted work from Celltrion: DHY, WP, MT, RJ, MA-B, PH, VK, LM-O, PM, MP, ER and SS received research grants and/or consultancy fees, and logistics support; SJL, SG-U, OZ and NP received research grants and/or consultancy fees only; HUK is a full-time employee of Celltrion. MT has received additional research grants from Celltrion and attended a Celltrion plant visit. UM-L has received payment for lectures from Celltrion.

Patient consent Obtained.
Ethics approval The protocol was reviewed and approved by each site's institutional review board or independent ethics committee.

Provenance and peer review Not commissioned; externally peer reviewed.

Data sharing statement All data available for this paper are included in the manuscript and online supplementary appendices.

Open Access This is an Open Access article distributed in accordance with the Creative Commons Attribution Non Commercial (CC BY-NC 3.0) license, which permits others to distribute, remix, adapt, build upon this work non-commercially, and license their derivative works on different terms, provided the original work is properly cited and the use is non-commercial. See: http://creativecommons.org/ licenses/by-nc/3.0/

\section{REFERENCES}

1 Maini R, St Clair EW, Breedveld F, et al. Infliximab (chimeric anti-tumour necrosis factor alpha monoclonal antibody) versus placebo in rheumatoid arthritis patients receiving concomitant methotrexate: a randomised phase III trial. ATTRACT Study Group. Lancet 1999:354:1932-9.

2 Dörner T, Strand V, Castañeda-Hernández G, et al. The role of biosimilars in the treatment of rheumatic diseases. Ann Rheum Dis 2013;72:322-8.

3 Park W, Hrycaj P, Jeka S, et al. A randomised, double-blind, multicenter, parallel-group, prospective phase 1 study comparing the pharmacokinetics, safety and efficacy of CT-P13 and innovator infliximab in patients with ankylosing spondylitis: The PLANETAS study. Ann Rheum Dis 2013. doi:10.1136/annrheumdis-2012-203091

4 Felson DT, Smolen JS, Wells G, et al. American College of Rheumatology/European League against Rheumatism provisional definition of remission in rheumatoid arthritis for clinical trials. Ann Rheum Dis 2011;70:404-13.

5 World Health Organization. Commercial serodiagnostic tests for diagnosis of tuberculosis: policy statement. Geneva: WHO, 2011.

6 National Institute of Clinical Excellence guideline. Clinical diagnosis and management of tuberculosis, and measures for its prevention and control 2011 [Online]. 2011. http:// guidance.nice.org.uk/cg117/niceguidance/pdf/english (accessed 5 Dec 2012).

7 Dasgupta A, Lawson KA, Wilson JP. Evaluating equivalence and noninferiority trials. Am J Health Syst Pharm 2010;67:1337-43.

8 Committee for Medicinal Products for Human Use (CHMP). Guideline on the choice of the non-inferiority margin (CPMP/2158/99). 27 July 2005. http://www.emea. europa.eu/docs/en_GB/document_library/Scientific_guideline/2009/09/ WC500003636.pdf (accessed 5 Dec 2012).

9 International Conference on Harmonisation of Technical Requirements for Registration of Pharmaceuticals for Human Use. ICH harmonised tripartite guideline: choice of control group and related issues in clinical trials (E10), dated 20 July 2000 [Online]. http://www.ich.org/fileadmin/Public_Web_Site/ICH_Products/ Guidelines/Efficacy/E10/Step4/E10_Guideline.pdf (accessed 5 Dec 2012).

10 Schiff M, Keiserman M, Codding C, et al. Efficacy and safety of abatacept or infliximab vs placebo in ATTEST: a phase III, multi-centre, randomised, double-blind, placebo-controlled study in patients with rheumatoid arthritis and an inadequate response to methotrexate. Ann Rheum Dis 2008;67:1096-103.

11 Zhang FC, Hou Y, Huang F, et al. Infliximab versus placebo in rheumatoid arthritis patients receiving concomitant methotrexate: A preliminary study from China. APLAR J Rheumatol 2006;9:127-30.

12 Abe T, Takeuchi T, Miyasaka N, et al. A multicenter, double-blind, randomized, placebo controlled trial of infliximab combined with low dose methotrexate in Japanese patients with rheumatoid arthritis. J Rheumatol 2006;33:37-44.

13 Westhovens R, Yocum D, Han J, et al. The safety of infliximab, combined with background treatments, among patients with rheumatoid arthritis and various comorbidities: a large, randomized, placebo-controlled trial. Arthritis Rheum 2006;54:1075-86.

14 Skogh T, Gustafsson D, Kjellberg M, et al. Twenty eight joint count disease activity score in recent onset rheumatoid arthritis using $C$ reactive protein instead of erythrocyte sedimentation rate. Ann Rheum Dis 2003;62:681-82.

15 Smolen JS, Van Der Heijde DM, St Clair EW, et al.; Active-Controlled Study of Patients Receiving Infliximab for the Treatment of Rheumatoid Arthritis of Early Onset (ASPIRE) Study Group. Predictors of joint damage in patients with early rheumatoid arthritis treated with high-dose methotrexate with or without concomitant infliximab: results from the ASPIRE trial. Arthritis Rheum 2006:54:702-10.

16 Remicade Summary of Product Characteristics. http://www.ema.europa.eu (accessed 5 Dec 2012).

17 St Clair EW, van der Heijde DM, Smolen JS, et al. Combination of infliximab and methotrexate therapy for early rheumatoid arthritis: a randomized, controlled trial. Arthritis Rheum 2004;50:3432-43.

18 World Health Organization. Global tuberculosis report, 2012. Geneva: WHO, 2012.

19 Bendtzen K, Geborek P, Svenson M, et al. Individualized monitoring of drug bioavailability and immunogenicity in rheumatoid arthritis patients treated with the tumor necrosis factor alpha inhibitor infliximab. Arthritis Rheum 2006:54:3782-9.

20 Pascual-Salcedo D, Plasencia C, Ramiro S, et al. Influence of immunogenicity on the efficacy of long-term treatment with infliximab in rheumatoid arthritis. Rheumatology (Oxford) 2011;50:1445-52. 